\title{
Comparative analysis of L-carnitine production by Yarrowia lipolytica in different culture conditions in biofuel waste and fatty acid-poor medium for commercial purposes
}

\section{Monika Elżbieta Jach ( $\square$ monijach@kul.pl)}

John Paul II Catholic University in Lublin https://orcid.org/0000-0002-4932-3260

Konrad Kubiński

John Paul II Catholic University of Lublin: Katolicki Uniwersytet Lubelski Jana Pawla II

Marek Juda

Medical University of Lublin: Uniwersytet Medyczny w Lublinie

\section{Ewa Sajnaga}

John Paul II Catholic University of Lublin: Katolicki Uniwersytet Lubelski Jana Pawla II

\section{Tomasz Baj}

Medical University of Lublin: Uniwersytet Medyczny w Lublinie

Anna Malm

Medical University of Lublin: Uniwersytet Medyczny w Lublinie

\section{Research}

Keywords: biofuel waste, fatty acids, fatty-rich medium, fatty acid-poor medium, L-carnitine, oleaginous yeast, Yarrowia lipolytica

Posted Date: September 7th, 2021

DOl: https://doi.org/10.21203/rs.3.rs-864598/v1

License: (c) (i) This work is licensed under a Creative Commons Attribution 4.0 International License. Read Full License 


\section{Abstract \\ Background}

Yarrowia lipolytica is an oleaginous yeast with the ability to grow in a variety of hydrophilic and hydrophobic substrates, including industrial wastes, in which it produces and accumulates various nutrients.

\section{Methods}

The aim of the present study was to examine the presence of free L-carnitine in the biomasses of two Yarrowia lipolytica strains (A-101 and ATCC 9793) growing in biofuel waste and YPD medium. The cultivations of $Y$. lipolytica were performed in aerobic conditions at different temperatures $\left(20-30^{\circ} \mathrm{C}\right)$ and $\mathrm{pH}$ values (4.0-7.0) of the media with and without the addition of precursors for L-carnitine production (trimethyllysine, iron, and L-ascorbic acid) in a laboratory scale or other substances (chromium, selenite, or zinc) in a pilot plant scale.

\section{Results}

Both tested Y. lipolytica strains grown in fatty acid-poor YPD medium contained endogenous free Lcarnitine in their biomass with a maximum of $22.85 \mathrm{mg} / 100 \mathrm{~g}$ of wet biomass. The addition of Lcarnitine precursors to the YPD medium exerted a significant effect on L-carnitine concentration in the yeast biomass, increasing it up to $250 \%$. In turn, the biomass of both tested $Y$. lipolytica strains cultivated in the biofuel waste, irrespective of the culture conditions, contained below $1 \mathrm{mg}$ of L-carnitine/ $100 \mathrm{~g}$ of wet biomass. However, the supplementation of the culture media with the L-carnitine precursors significantly increased the yield of the yeast biomass by $20-30 \%$ in the non-fermentable biofuel waste cultures. Moreover, the addition of chromium (III) chloride into the biofuel waste caused an increase in the free L-carnitine concentration in the yeast biomass up to $2.24 \mathrm{mg} / 100 \mathrm{~g}$ of dry weight.

\section{Conclusion}

Biomass of $Y$. lipolytica grown in the fat-poor medium contained free L-carnitine, in contrast to the biomass grown in the fat-rich biofuel waste. The very low amounts of L-carnitine in the biomass of $Y$. lipolytica grown in the crude biofuel waste suggest that the yeast is able to utilize almost the entire pool of free L-carnitine for growth and nutritional biomass production. However, the addition of chromium to the biofuel waste contributed to an increase in L-carnitine concentration in Y. lipolytica biomass.

\section{Background}


L-carnitine or $\gamma$-trimethylamino- $\beta$-hydroxybutyric acid is a ubiquitous water-soluble quaternary amine compound $[1,2,3]$. It is synthesized by most eukaryotic organisms, including some yeast, from amino acids: lysine as a precursor and methionine or S-adenosyl methionine as a methyl donor [3, 4]. In humans, endogenous synthesis of L-carnitine occurs chiefly in the liver. However, it must be complemented through dietary uptake. Since it is regarded to be a quasi-nutrient or conditionally essential nutrient, Lcarnitine deficiencies sometimes cause life-threatening disorders. As an important factor in cellular metabolism, L-carnitine binds fatty acids and transfers them to the mitochondria for $\beta$-oxidation required for generation of energy. Without L-carnitine, the mitochondrial inner membrane is impermeable to fatty acids $[1,5,6]$. L-carnitine transports long- to short-chain fatty acids out of the peroxisome, where $\beta$ oxidation is started, into the mitochondria, where the process is completed, by reversible esterification of the $\beta$-carbon hydroxyl group with a fatty acid to form $O$-acyl-carnitine. Cytosolic acyl-carnitine is then transported by carnitine acetyltransferases (CATs) into the mitochondrial matrix with a simultaneous 1:1 exchange with intramitochondrial free L-carnitine located within the mitochondrial inner membrane [1]. CATs transfer the coenzyme A (CoA) group of acetyl-CoA to carnitine; hence, acetyl-carnitine is biosynthesized, which can be transferred via the peroxisomal and mitochondrial membranes to the tricarboxylic acid (TCA) cycle [7]. Interestingly, the supplementation with L-carnitine results in more effective fatty acids transport to the mitochondria, where their decomposition occurs in the $\beta$-oxidation process [8].

The best-known yeast Saccharomyces cerevisiae is unable to synthesize L-carnitine. However, this yeast possesses enzymatic activities, especially CATs, which allow the uptake of L-carnitine from the environment $[4,7,10]$. Studies reported elsewhere $[3,12-14]$ revealed that some oleaginous yeast, e.g. Candida albicans and Yarrowia lipolytica, synthesize de novo endogenous L-carnitine. Similar to $S$. cerevisiae, $C$. albicans and $Y$. lipolytica have the activity of three forms of CATs; however, the oleaginous yeast is able to grow in a medium containing fatty acids without supplementary carnitine $[3,15]$. Additionally, Y. lipolytica possesses proteins for transport and activation of fatty acids (i.e. Faa1p, Pxa1p, Pxa2p, and Ant1p) similar to those of $S$. cerevisiae. However, the activation and mechanism of the peroxisomal transport of fatty acids into $Y$. lipolytica mitochondria differ considerably from that in $S$. cerevisiae [15]. In contrast to $S$. cerevisiae, $Y$. lipolytica has six additional acetyl-CoA oxidases (encoded by POX1-6 genes) with different chain-length specificities, which allow direct utilization of fatty acid-rich feedstock through complete oxidation using intermediates of $\beta$-oxidation $[9,16-18]$. When yeasts grow on a fatty acid-poor or fat-fee carbon source, peroximal structures cannot be identified. In turn, when they grow on fatty acid-containing media, the proliferation of peroxisomes is clearly detected. Thus, peroxisomes seem to be strictly required for yeasts to catabolize fatty acids. They play the sole role in $\beta$ oxidation in the fatty acid degradation process causing the formation of acetyl-CoA in the peroxisome. Therefore, L-carnitine is important for the acetyl shuttle mechanism, transferring long-chain fatty acids between peroxisomes and mitochondria for subsequent $\beta$-oxidation during yeast growth on nonfermentable carbon sources such as fatty acids, acetate, and ethanol [4, 7]. During yeast growth on these carbon sources, acetyl units are only produced in the cytosol and need to be transferred to the mitochondrial TCA cycle and to the peroxisomal/cytosolic glyoxylate cycle [9]. 
The availability of fatty acids from industrial by-products promotes the use of fatty acid-enriched feedstock as a cheap carbon source by oleaginous yeast [12]. It has been shown that $Y$. lipolytica grown on a medium with different fatty wastes is a natural source of such nutritional components as single cell oils (especially mono-unsaturated fatty acids and saturated cocoa-butter equivalents), protein (i.e. single cell protein, SCP), amino acids, and B-group vitamins, including vitamin B12 [19-27]. In this respect, this yeast occupies an important place in pharmaceutical, feed, and food industry [23]. Moreover, the use of this yeast biomass as an additional nutritional supplement can support a solution to the problem of food scarcity in the ever-growing human population, especially in developing countries such as India and Burkina Faso [23, 28]. In 2019, the European Food and Safety Authority (EFSA) authorized the use of dried and heat-killed $Y$. lipolytica biomass as a novel food in dietary supplements intended for the general population above 3 years of age [29]. Furthermore, fatty waste biodegradation by this yeast is regarded as particularly relevant for environmental protection [27, 30-33]. Moreover, growing in nitrogen starvation conditions during lipogenesis, $Y$. lipolytica is also used for production of diesel-like fuels and oleochemicals from carbohydrate resources [34].

Previously, we reported that $Y$. lipolytica is able to produce protein, amino acids and generally an appropriate amount of vitamin B-enriched biomass when grown in biofuel waste [21, 22, 26, 35]. The mentioned studies were focused on Y. lipolytica A-101, which is a valuable industrial strain used to produce biomass rich in various nutrients. Dried biomass of the A-101 strain cultivated in biofuel waste is sold on the European market as a commercial nutritional feed additive. However, there is hardly any information about the concentrations of free L-carnitine in Y. lipolytica biomass in literature. Therefore, in this study, two Y. lipolytica strains, namely the industrial A-101 strain and the standard reference strain from the American Type Culture Collection (ATCC), were examined for L-carnitine content in their biomasses depending on the medium, fat-rich biofuel waste, and fatty acid-poor YPD medium.

\section{Results}

\section{Influence of culture conditions on the L-carnitine concentration in Y. lipolytica biomass}

The L-carnitine concentration in the yeast biomass was tested using both $Y$. lipolytica A-101 and $Y$. lipolytica ATCC 9793 strains growing in two culture media: biofuel waste (SK medium) and standard laboratory YPD. The first step consisted in the determination of the L-carnitine concentration in the biomass of the industrial A-101 strain cultivated in biofuel waste. The level of L-carnitine in the A-101 biomass grown in biofuel waste was below $1 \mathrm{mg} / 100 \mathrm{~g}$ of wet biomass in all tested culture conditions (data not shown). In the light of the obtained results, we decided to use the standard YPD medium as another culture medium. As shown in Fig. 1A, B, free L-carnitine was detected in the biomass of both $Y$. lipolytica strains cultured in the YPD medium in the different culture conditions. The obtained biomasses of $Y$. lipolytica strains enriched in L-carnitine exhibit different sensitivities to temperature and $\mathrm{pH}$. This trial evaluated the effect of different values of $\mathrm{pH}$ (from 4.0 to 7.0 ) and temperature (form 20 to $30^{\circ} \mathrm{C}$ ). In 
the case of Y. lipolytica ATCC 9793, the maximum concentration of L-carnitine $(22.85 \mathrm{mg} / 100 \mathrm{~g}$ of wet biomass) was reached at the temperature of $20^{\circ} \mathrm{C}$ and pH 6.0 (Fig. 1B). This result was comparable to that obtained at the temperature of $30^{\circ} \mathrm{C}$ and pH 5.0 (Fig. 1A). The differences were not statistically significant $(P>0.05)$. On the contrary, in the industrial standard conditions $\left(30^{\circ} \mathrm{C}, \mathrm{pH} 6.0\right)$ in the YPD medium, the L-carnitine level produced by $Y$. lipolytica ATCC 9793 was 2 times lower $(9.93 \mathrm{mg} / 100 \mathrm{~g}$ of wet biomass) than that obtained at the temperature of $30^{\circ} \mathrm{C}$ and $\mathrm{pH} 5.0$. These differences were statistically significant $(P<0.01)$. The concentration of $\mathrm{L}$-carnitine in the biomass of $Y$. lipolytica A-101 was statistically lower than in the Y. lipolytica ATCC 9793 biomass $(P<0.01)$ obtained in the same conditions (Fig. 1). However, Y. lipolytica A-101 growing in the YPD medium at the temperature of $30^{\circ} \mathrm{C}$ and $\mathrm{pH} 5.0$ produced a 2.5 times higher level of L-carnitine $(7.09 \mathrm{mg} / 100 \mathrm{~g}$ of wet biomass) than in the industrial standard culture conditions $\left(30^{\circ} \mathrm{C}, \mathrm{pH} 6.0\right)$ (Fig. 1A). These differences were statistically significant $(P<0.01)$.

A Bland-Altman plot (Fig. 2) comparing the concentration of L-carnitine and protein [21] in the biomasses of Y. lipolytica A-101 and ATCC 9793 was also performed to determine the difference in the L-carnitine and protein production ability between the two strains. Irrespective of the culture parameters, both of the strains produced comparable amount of proteins but it existed significant difference in production of Lcarnitine between these strains. Y. lipolytica ATCC 9793 produced significantly more L-carnitine in comparison with A-101 strain.

\section{Influence of precursors on the L-carnitine concentration in Y. lipolytica biomass yields}

The addition of a low concentration of trimethyllysine hydrochloride $(0.01 \mathrm{~g} / \mathrm{L}), \mathrm{L}$-ascorbic acid $(0.002$ $\mathrm{g} / \mathrm{L})$, and iron(II) sulfate $(0.001 \mathrm{~g} / \mathrm{L})$, as precursors of $\mathrm{L}$-carnitine synthesis to the YPD medium $[3,4,9]$ only slightly influenced the L-carnitine concentration in the Y. lipolytica ATCC 9793 biomass (Table 1). The differences in the L-carnitine concentration were not statistically significant in comparison to the Lcarnitine level in the biomass of the ATCC 9793 strain grown in the medium without these supplementations. However, a $25 \%$ increase in the L-carnitine content $(P<0.05)$ was reported in the biomass of the reference $Y$. lipolytica ATCC 9793 strain grown in the YPD medium supplemented with the higher concentration of iron(II) sulfate $(0.01 \mathrm{~g} / \mathrm{L})$ and trimethyllysine hydrochloride $(0.1 \mathrm{~g} / \mathrm{L})$ and the same concentration of L-ascorbic acid $(0.002 \mathrm{~g} / \mathrm{L})$. In the case of the $Y$. lipolytica A-101 strain, the addition of the low concentration of iron (II) sulfate $(0.001 \mathrm{~g} / \mathrm{L})$, trimethyllysine hydrochloride $(0.01 \mathrm{~g} / \mathrm{L})$, and $\mathrm{L}$-ascorbic acid $(0.002 \mathrm{~g} / \mathrm{L})$ resulted in a $250 \%$ increase in the L-carnitine concentration in the yeast biomass in comparison to the A-101 strain cultivated in the medium without these additives (Table 1). These differences were statistically significant $(P<0.01)$. The further increase in the concentrations of iron (II) sulfate $(0.01 \mathrm{~g} / \mathrm{L})$ and trimethyllysine hydrochloride $(0.1 \mathrm{~g} / \mathrm{L})$ in the YPD medium with $\mathrm{L}$-ascorbic acid $(0.002 \mathrm{~g} / \mathrm{L})$ caused no statistically significant change in the L-carnitine level in the A-101 strain biomass in comparison with results obtained in the biomass of $Y$. lipolytica grown with lower amount of these compounds. 
Table 1

L-carnitine concentration in the wet biomass of Yarrowia lipolytica strains cultured in biofuel waste and YPD medium.

\begin{tabular}{|c|c|c|c|c|}
\hline \multirow[t]{3}{*}{ medium } & \multicolumn{4}{|c|}{$\begin{array}{l}\text { L-carnitine concentration (mg/100g wet biomass) } \\
\text { Mean } \pm \text { Standard deviation (SD) }\end{array}$} \\
\hline & \multicolumn{2}{|c|}{ Y. lipolytica A-101 } & \multicolumn{2}{|c|}{ Y. lipolytica ATCC 9793} \\
\hline & Biofuel waste & YPD medium & Biofuel waste & YPD medium \\
\hline unsupplemented & $<1.00$ & $2.80 \pm 0.05$ & $<1.00$ & $9.93 \pm 0.50$ \\
\hline $\begin{array}{l}\text { supplemented } \\
\text { trimethyllysine }(0.01 \mathrm{~g} / \mathrm{L}) \text {, } \\
\text { iron(II) }(0.001 \mathrm{~g} / \mathrm{L}) \\
\text { L-ascorbic acid }(0.002 \mathrm{~g} / \mathrm{L})\end{array}$ & $<1.00$ & $9.80 \pm 0.49 * *$ & $<1.00$ & $10.99 \pm 0.55$ \\
\hline $\begin{array}{l}\text { supplemented } \\
\text { trimethyllysine }(0.1 \mathrm{~g} / \mathrm{L}) \text {, } \\
\text { iron(II) }(0.01 \mathrm{~g} / \mathrm{L}) \text {, } \\
\mathrm{L} \text {-ascorbic acid }(0.002 \mathrm{~g} / \mathrm{L})\end{array}$ & $<1.00$ & $10.74 \pm 0.52$ ** & $<1.00$ & $12.41 \pm 0.62$ ** \\
\hline
\end{tabular}

${ }^{\star \star} P<0.01$ indicates significant difference compared with the reference unsupplemented cultivation.

The yeast were cultivated $12 \mathrm{~h}$, at $30^{\circ} \mathrm{C}, \mathrm{pH} 6.0,12 \mathrm{~h}$.

We also tested the effect of the addition of the mixture of the factors, i.e. trimethyllysine hydrochloride $(0.1 \mathrm{~g} / \mathrm{L})$, iron (II) sulfate $(0.01 \mathrm{mg} / \mathrm{L})$, and L-ascorbic acid $(0.002 \mathrm{~g} / \mathrm{L})$, to the SK medium (biofuel waste) on the yeast biomass yield (growth density, $\mathrm{OD}_{600}$ ), in comparison to the medium without these supplements (Fig. 3A, B). After 12-hour cultivation, the biomass quantity of both yeast strains cultured in the SK medium without the additives was quite satisfactory $\left(\mathrm{OD}_{600} 1.5\right)$. However, the addition of these $\mathrm{L}-$ carnitine precursors caused a significant increase in the yield of both $Y$. lipolytica strains $(P<0.05)$. After 10-hour yeast cultivation, the addition of the mixture led to a $20 \%$ and $30 \%$ increase in the biomass yield of the reference Y. lipolytica ATCC 9793 strain and the A-101 strain, respectively.

\section{Concentration of free L-carnitine in the Yarrowia powder}

The content of free L-carnitine in the dried Y. lipolytica A-101 biomass (so-called Yarrowia powder) was determined in probes obtained through standard production of seven independent batches in a pilot plant scale in biofermentors. Additionally, chromium-, selenium-, or zinc-enriched yeast biomass was derived from cultures of the A-101 strain grown in the presence of a source of an appropriate micro or macro element. Therefore, six batches (per two batches) were cultivated using supplemented biofuel waste (the SK medium): chromium(III) chloride (15 mg/L), sodium hydrogen selenite (15 mg/L), and zinc sulfate 
(1200 mg/L). After drying, we obtained Yarrowia powder, which was amorphous hygroscopic beigecoloured powder with a slight yeast odor. L-carnitine was only detected in the dry biomass of Y. lipolytica cultured in the chromium-supplemented SK medium. In this case, the free L-carnitine concentration was comparable in both batches (mean $2.31 \mathrm{mg} \pm 0.13 / 100 \mathrm{~g}$ of dried biomass) (Table 2). However, the dry biomass of $Y$. lipolytica, grown in all studied chromium-unsupplemented biofuel waste contained below 1 $\mathrm{mg}$ of L-carnitine/100 $\mathrm{g}$ of dry weight.

Table 2

Concentration of protein and free L-carnitine in the dried Yarrowia lipolytica A-101 biomass (Yarrowia powder) obtained after culturing in the SK medium (biofuel waste) in a pilot plant scale.

\begin{tabular}{|c|c|c|}
\hline Batch number ${ }^{1}$ & $\begin{array}{l}\text { Protein content } \\
\text { (\% of dry weight) }^{2}\end{array}$ & $\begin{array}{l}\text { Concentration of L-carnitine } \\
\text { (mg/ } 100 \mathrm{~g} \text { of dry weight) } \\
\text { Mean } \pm \text { Standard deviation (SD) }\end{array}$ \\
\hline 1 (unsupplemented) & 49.3 & $<1.00$ \\
\hline 2 (supplemented $\mathrm{CrCl}_{3}$ ) & 41.9 & $2.37 \pm 0.13$ \\
\hline 3 (supplemented $\mathrm{NaHSeO}_{3}$ ) & 42.6 & $<1.00$ \\
\hline 4 (supplemented $\mathrm{ZnSO}_{4}$ ) & 43.7 & $<1.00$ \\
\hline 5 (supplemented $\mathrm{ZnSO}_{4}$ ) & 44.8 & $<1.00$ \\
\hline 6 (supplemented $\mathrm{NaHSeO}_{3}$ ) & 42.0 & $<1.00$ \\
\hline 7 (supplemented $\mathrm{CrCl}_{3}$ ) & 41.9 & $2.24 \pm 0.11$ \\
\hline Mean & 45.6 & 2.31 \\
\hline
\end{tabular}

\section{Discussion}

In the present study, we examined the effect of the culture conditions, two different media, and supplementation of the media on the level of free L-carnitine in the biomass of Y. lipolytica strains. The results confirm other findings $[7,22,35-38]$ revealing that the fermentation process parameters can have a significant impact on improvement of the nutrient content in the biomass of the studied yeast strains. However, we showed that the concentration of free L-carnitine in the yeast biomass depended primarily on the medium used, and, to some extent, on the strains and culture conditions.

The first medium used was biofuel waste (the SK medium) with high contents of fatty acids. It is known that $Y$. lipolytica growing in fatty substrates is able to accumulate and store lipids $[18,24,37,39-40]$. Since extracellular carbon sources were depleted, the yeast utilized its own storage lipids (body lipids) as 
a carbon and energy source, increasing the production of proteins $[19,20,41,42]$. Interestingly, a knockout of the sextuple POX genes in Y. lipolytica causes inability of this yeast to degrade storage lipids, leading to over-accumulation of fats in yeast cells $[15,18]$. Therefore, the biosynthesis of cellular proteins or polysaccharides and the fat-free biomass production are competitive to lipid accumulation [42, 43]. We found previously that both Y. lipolytica strains (ATCC 9793 and A-101) utilized biofuel waste (the SK medium) to produce biomass with a high concentration of protein and amino acids, especially the industrial A-101 strain $[21,35]$. In the present study of both $Y$. lipolytica strains grown in the biofuel waste at a temperature range from $20^{\circ} \mathrm{C}$ to $30^{\circ} \mathrm{C}$ and different $\mathrm{pH}$ values (from 4.0 to 7.0 ), we did not notice a significant influence in the L-carnitine concentrations. The level of L-carnitine was below $1 \mathrm{mg} / 100 \mathrm{~g}$ of wet biomass in all fermentation samples (data not shown). We can hypothesize that, irrespective of the culture conditions, both $Y$. lipolytica strains used the entire pool of endogenous free L-carnitine to utilize fatty acids from biofuel waste to grow and produce protein-enriched biomass. It is worth emphasizing that carnitine can also be used as a sole nitrogen source, most commonly through the glycine betaine pathway, where glycine conversion to serine is followed by deamination to form pyruvate and ammonia [1]. It was proved that $Y$. lipolytica grown in biofuel waste was able to produce all amino acids [21, 35]. However, it should be added that the reference Y. lipolytica ATCC 9793 strain did not grow at low pH (4.0 or 5.0) in the biofuel waste, in contrast to the growth in the standard YPD medium. In turn, the Y. lipolytica A-101 strain was able to grow at low pH (4.0 or 5.0) in the biofuel waste. Our results coincide with those reported by Swigers et al. [4], who found that L-carnitine was strictly required for yeast growth on nonfermentable carbon sources such as acetate, ethanol, fatty acids, and glycerol, which do not contain carnitine. Mutants with deletion of all three CAT genes ( $\Delta$ cit2 strain) were unable to grow in media containing these carbon sources. However, supplementation of yeast extract, which contains a sufficient amount of carnitine, or free L-carnitine into these media, caused growth of the $\Delta$ cit2 strain due to absorption of carnitine from the environment [4].

Another study [3] showed that another oleaginous yeast $C$. albicans strain, with deletion of all four genes determining the L-carnitine synthesis pathway, was unable to grow on fatty acids and to utilize either acetate or ethanol as carbon sources. In turn, a transfer of the gene encoding acetyl-CoA oxidase from $Y$. lipolytica to $S$. cerevisiae enabled $S$. cerevisiae to grow on fatty acid-rich feedstock [12]. The possibility of biofuel waste utilization as a substrate by $Y$. lipolytica mainly depended on the strains and culture conditions. Our previous studies revealed that the temperature of $30^{\circ} \mathrm{C}$ and $\mathrm{pH} 5.0$ were more suitable for production of SPC, amino acids, and B-group vitamins by $Y$. lipolytica strains cultivated in both YPD and SK media (biofuel waste) than at standard industrial conditions $\left(30^{\circ} \mathrm{C}, \mathrm{pH} 6.0\right)[21,22,26,35]$. Noteworthy, the culture parameters (i.e. temperature and $\mathrm{pH}$ ) also strongly affect lipase activities. The maximum activity of lipases produced by $Y$. lipolytica is noted at a temperature between $30^{\circ} \mathrm{C}$ and $40^{\circ} \mathrm{C}$ and $\mathrm{pH} 5.0$ [43]. Moreover, these culture conditions significantly influence $Y$. lipolytica lipid accumulation during the primary anabolic growth when cultivated on fatty substrates [36-38].

The standard laboratory YPD medium, used in this study as supplementary, contains yeast extract with only $0.10 \%-0.15 \%$ of fatty acids. Yeast extract is mainly added to the medium as a nitrogen source; however, it also contains several biocomponents, including sufficient amounts of carnitine, to 
complement the carnitine requirements of yeast $[4,7]$. It was reported that the effect of yeast extract on Lcarnitine biosynthesis was dissimilar among tested fungal strains. Yeast extract had a slight effect on the increasing in the L-carnitine concentration in Aspergillus oryzae and Rhizopus oryzae biomasses but did not influence L-carnitine production in Neurospora intermedia. Moreover, it was found that, as long as glucose is present in the medium, it serves as the primary energy and carbon source, preventing Lcarnitine consumption. However, after glucose exhaustion, although the biomass weight kept increasing, the concentration of free L-carnitine in the biomass started to decrease. Therefore, the prolongation of the cultivation time caused the fungus to consume glucose entirely and then L-carnitine was utilized as a carbon source [7]. In our study, endogenous free L-carnitine in both tested Y. lipolytica strains was detected when they were cultivated in YPD medium. The highest levels of L-carnitine in this medium in the industrial $Y$. lipolytica A-101 biomass were obtained when it was grown at a temperature of $30^{\circ} \mathrm{C}$ and $\mathrm{pH} 7.0$, although promising results were also obtained at pH 5.0 (Fig. 1A). The reference ATCC 9793 strain cultivated in YPD at a temperature of $20^{\circ} \mathrm{C}$ and $\mathrm{pH} 6.0$ contained two times more L-carnitine than the industrial A-101 strain (Fig. 1B). However, a similar amount of L-carnitine in the ATCC 9793 biomass was obtained when the strain was cultivated at the temperature of $30^{\circ} \mathrm{C}$ and pH 5.0 (Fig. 1A). We showed previously that these conditions were optimal to obtain protein-enriched biomass of $Y$. lipolytica cultured in biofuel waste $[21,35]$. Thus, the ability to produce nutritional elements is not a static property, and it can be considerably affected by fermentation process parameters. However, as shown in Fig. 2, reference Y. lipolytica ATCC 9793 grown in YPD medium, irrespective of the culture parameters, proved to be a better producer of free L-carnitine than another investigated strain.

In the presented work, the effect of precursors for L-carnitine biosynthesis was observed as well (Fig. 2B). Strijbis et al. $[3,9]$ reported that trimethyllysine $(T M L)$ is a main precursor to synthesize carnitine. TML is a component of the first enzyme of the carnitine biosynthesis pathway, namely TML dioxygenase (TMLD), which requires the presence of ascorbate (vitamin C) and iron(II) for its enzymatic activity. The results confirmed that the addition of L-carnitine precursors increased the growth and quantity of yeast biomass growing in the fat-acid-rich medium, i.e. biofuel waste. This confirms the previous reports that the growth of such oleaginous yeasts as $C$. albicans, Y. lipolytica, or engineered $S$. cerevisiae strains on non-fermentable fat-rich carbon sources is possible only in the presence of L-carnitine biosynthesis intermediates $[3,6,12]$. In turn, in wild $S$. cerevisiae, peroxisomal membranes are impermeable to acetylCoA, when the yeast is cultivated on fatty acids as carbon source. Therefore, wild $S$. cerevisiae are not able to grow in fat-rich waste substrates [42] in contrast to $Y$. lipolytica. In this respect, production of nutritional yeast biomass by oleaginous species on available inexpensive wastes used as carbon and energy sources (e.g. biofuel waste) is desired by industry in the broad sense.

We also observed a stimulatory effect of chromium on the free L-carnitine production. Trivalent chromium, an essential trace element, as diet components improving glucose uptake and fat metabolism was reported [44]. Moreover, the deficiency of trivalent $\mathrm{Cr}$ may induce symptoms comparable to those associated with diabetes in mammals [45]. Our experimental results showed that the introduction of water-soluble chromium ( $\mathrm{Cr}(\mathrm{III})$ ) salt as a component of biofuel waste as the culture medium for $Y$. lipolytica resulted in production of a slight amount of free L-carnitine by the yeast. This implies that $\mathrm{Cr}$ 
supported L-carnitine metabolism in some way in the yeast cells. However, the issue of the chemical dependencies between $\mathrm{Cr}$ and L-carnitine in yeast cells needs further investigations. Additionally, we supplemented zinc and selenium into biofuel waste in the pilot plant scale to obtain zinc- or seleniumenriched yeast biomass, but we did not observe a significant increase in the L-carnitine concentrations.

\section{Conclusions}

Yarrowia lipolytica growing in fatty acid-enriched substrates, e.g. biofuel waste in strictly aerobic environments probably uses the entire pool of endogenous L-carnitine for growth and production of biomass. Hence, crude biofuel waste, as an inexpensive substrate, can be utilized by $Y$. lipolytica for production of high-value nutritional compounds but at present, it cannot be used for free L-carnitine. However, further studies on process optimization and cultivation medium based on biofuel waste need to be carried out in order to clarify the potential of the industrial Y. lipolytica A-101 strain for production of Lcarnitine-enriched yeast biomass. The use of L-carnitine precursors contributes to production of greater amounts of L-carnitine in fatty acid-poor medium and can increase the yield of $Y$. lipolytica grown in both fatty acid-poor medium and biofuel waste. Moreover, $Y$. lipolytica growing in fatty acid-poor media or substrates with a small amount of fatty acids, especially various bio-wastes, can be applied as an Lcarnitine producer.

\section{Methods}

\section{Microbial Strains}

In the research, the industrial nutrient productive wild-type yeast Yarrowia lipolytica A-101 strain was obtained from Skotan S.A. (Poland) and as the reference yeast Y. lipolytica ATCC 9793 strain was obtained from LGC Standards.

\section{Production, harvesting of Y. lipolytica biomass, and yeast growth conditions}

Y. lipolytica was cultured in two culture media: an industrial fat-rich SK medium and the chemically defined fatty acid-poor YPD medium (Difco). The SK medium is a waste from biofuel production, which is normally used by Skotan S.A for production of $Y$. lipolytica A-101 biomass rich in nutritional elements for commercial use. Biofuel is made through chemical reaction of vegetable oil with ethanol producing fatty acid esters (long-chain alkyl (methyl, ethyl, or propyl) esters). Crude biofuel waste consists of a mixture of vegetable oils with degumming and glycerol fractions (from $2-7 \% \mathrm{wt} / \mathrm{wt}$ ). The degumming fraction contains mainly phosphoric acid derivatives associated with fats and protein as well as free plant fats (up to $10 \%$ ), protein (up to $10 \%$ ), ash (up to $5 \%$ ). The SK medium as a biofuel waste also contains $\left(\mathrm{NH}_{4}\right)_{2} \mathrm{SO}_{4}(12.6 \mathrm{~g} / \mathrm{L})$, urea $(4.0 \mathrm{~g} / \mathrm{L}), \mathrm{MgSO}_{4}(1.0 \mathrm{~g} / \mathrm{L}), \mathrm{KH}_{2} \mathrm{PO}_{4}(0.5 \mathrm{~g} / \mathrm{L})$, and some amount of vitamins B. The mean concentration of these vitamins in $100 \mathrm{ml}$ of the medium is as follows: $0.9 \mathrm{mg}$ of thiamine, $3.65 \mathrm{mg}$ of riboflavin, $3.38 \mathrm{mg}$ of pyridoxine, $138 \mu \mathrm{g}$ of folic acid, and $6.2 \mu \mathrm{g}$ of cyanocobalamin. The SK 
medium was provided by Skotan S.A. (Poland). The biofuel waste, i.e. a partially refined, desalinated, and methanol-free by-product from biodiesel manufacture, was delivered by Lotos Group Refineries, Poland to Skotan S.A. By contrast, the YPD medium contains a small amount of fatty acids which origin from yeast extract. Yeast extract used for preparation of YPD medium (Difco) contains only $0.10 \%-0.15 \%$ of fatty acids. The biomass of $Y$. lipolytica A-101 was obtained in SK medium in standard culture conditions: i.e. temperature of $30^{\circ} \mathrm{C}$ and $\mathrm{pH}$ 6.0, which were established earlier by Skotan S.A. These industrial culture conditions were considered as reference ones in this study, while two experimental culture conditions were used: 1) variable temperature (from $20^{\circ} \mathrm{C}$ to $30^{\circ} \mathrm{C}$ ) and constant $\mathrm{pH}(6.0)$ values; 2 ) constant temperature $\left(30^{\circ} \mathrm{C}\right)$ and variable $\mathrm{pH}$ (from 4.0 to 7.0 ) values. The $\mathrm{pH}$ was adjusted to the required values by adding $1 \mathrm{M} \mathrm{NaOH}$ or $1 \mathrm{M} \mathrm{HCl}$, respectively. The sterile media in Erlenmeyer flasks (150 ml) were supplemented with $\mathrm{FeSO}_{4}$, trimethyllysine hydrochloride, and L-ascorbic acid. The following combinations were applied: a) iron(II) sulfate $(0.001 \mathrm{~g} / \mathrm{L})$, trimethyllysine hydrochloride $(0.01 \mathrm{~g} / \mathrm{L})$, and Lascorbic acid $(0.002 \mathrm{~g} / \mathrm{L})$ with the final $\mathrm{pH} 6.0$; b) iron(II) sulfate $(0.01 \mathrm{~g} / \mathrm{L})$, trimethyllysine hydrochloride $(0.1 \mathrm{~g} / \mathrm{L})$, and $\mathrm{L}$-ascorbic acid $(0.002 \mathrm{~g} / \mathrm{L})$ with the final $\mathrm{pH}$ 6.0. $Y$. lipolytica cultivated in the YPD broth at a temperature of $30^{\circ} \mathrm{C}$ and $\mathrm{pH} 6.0$ was the control culture. Y. lipolytica strains were cultured in Erlenmeyer flasks $(150 \mathrm{ml})$ and in a biofermentor $(100 \mathrm{~L})$ as a pilot plant scale as previously described $(21,26)$. The sterile SK medium in the biofermentor was prepared with and without chromium (III) chloride (15 mg/L); sodium hydrogen selenite $(15 \mathrm{mg} / \mathrm{L})$; or zinc sulfate $(1200 \mathrm{mg} / \mathrm{L})$. After 12 -hours cultivation, the biomass from the biofermentor was transferred into a tumble dryer and dried at $165-175^{\circ} \mathrm{C}$ for 1 hour; this yielded dried biomass called Yarrowia powder.

\section{Preparation of yeast disruption in bead mill}

Yeast cells were disintegrated with the use of a bead mill (Minilys homogenizer, Bertin Technologies) with the power of $250 \mathrm{~V} \mathrm{AC} / 50-60 \mathrm{~Hz}$, and speed $5000 \mathrm{rpm}$. The total working volume of the mill tube was ca $2 \mathrm{ml}$. Zirconium-glass beads (Bertin Technologies) with diameter of $0.5 \mathrm{~cm}$ were used in the experiments. For a single homogenization, $50 \mathrm{mg}$ of the $Y$. lipolytica cells were used. The cells were resuspended in $0.5 \mathrm{ml}$ Tris- $\mathrm{HCl}$ buffer, $\mathrm{pH} 7.5$. 3D beat-beating was carried out in cycles: $10 \times 1 \mathrm{~min}$. of homogenization and $0.5 \mathrm{~min}$. in the ice.

\section{L-carnitine analysis}

Total free L-carnitine in the yeast biomass was determined using an L-Carnitine Assay Kit according to the assay procedure (Abnova, Catalog № KA0860).

\section{Statistical analysis of data}

All data are expressed as a mean \pm SD (standard deviation) of three independent experiments. The differences between the concentrations of L-carnitine in the biomasses of $Y$. lipolytica strains growing at the different conditions were compared to Y. lipolytica ATCC A-101 cultured in the YPD medium at the temperature of $30^{\circ} \mathrm{C}$ and $\mathrm{pH} 6.0$ with two-sided student's $t$-test, using Statistica software version 12.0. The $P$ value $<0.05$ was considered statistically significant. 


\section{Abbreviations}

ATCC - the American Type Culture Collection; CATs - carnitine acetyltransferases; CoA - coenzyme A; EFSA - the European Food and Safety Authority; TCA - tricarboxylic acid; TML trimethyllysine; TMLD-TML dioxygenase.

\section{Declarations}

\section{Ethics approval and consent to participate}

Not applicable.

\section{Consent for publication}

Not applicable.

\section{Availability of data and materials}

The datasets generated for this study are available on request to the corresponding author.

\section{Competing interests}

The authors declare no competing interests.

\section{Funding}

This work was supported by the European Regional Development Fund under the Innovative Economy Operational Programme 2007-2013 [UDA-POIG-01.04.00-24-132/11-00].

\section{Authors' contributions}

Conceptualization, M.E.J. and A.M.; methodology, M.E.J., K.K. and A.M.; software, M.E.J., T.B. and A.M; validation, M.E.J., K.K. and A.M.; formal analysis, M.E.J. T.B. and A.M.; investigation, K.K.; resources, M.E.J., E.S., A.M; data curation, M.E.J. and K.K.; writing-original draft preparation, M.E.J.; writing-review and editing, M.E.J., E.S., K.K. and A.M; visualization, M.E.J. and T.B.; supervision, A.M.; project administration, M.E.J. and A.M.; funding acquisition, M.E.J. and A.M. All authors have read and agreed to the published version of the manuscript.

\section{Acknowledgements}

The authors wish to thank team of Wrocław University of Environmental and Life Sciences for isolation of Y. lipolytica A-101 strain.

\section{References}


1. Meadows JA, Wargo MJ. Carnitine in bacterial physiology and metabolism. Microbiol. 2015;161:1161-74.

2. Stephens FB, Constantin-Teodosiu D, Greenhaff PL. New insights concerning the role of carnitine in the regulation of fuel metabolism in skeleton muscle. J Physiol. 2007;581:431-44.

3. Strijbis K, van Roermund CWT, Hardy GP, van den Burg J, Bloem K, de Haan J, van Vlies N, Wanders RJA, Vaz FM, Distel B. Identification and characterization of a complete carnitine biosynthesis pathway in Candida albicans. FASEB J. 2009;23:2349-59.

4. Swiegers JH, Dippenaar N, Pretorius IS, Bauer FF. Carnitine-dependent metabolic activities in Saccharomyces cerevisiae: three carnitine acetyltransferases are essential in a carnitine-dependent strain. Yeast. 2001;18:585-95.

5. Flanagan JL, Simmons PA, Vehige J, Willcox MD, Garrett Q. Role of carnitine in disease. Nutr Metab. 2010;16:30. doi:10.1186/1743-7075-7-30.

6. van Rossum HM, Kozak BU, Niemeijer MS, Dykstra JC, Luttik MAH, Daran J-MG, van Maris AJA, Pronk JT. Requirements for carnitine shuttle-mediated translocation of mitochondrial acetyl moieties to the yeast cytosol. mBiol 2016;7; doi:e00520-16, 10.1128/mBio.00520 - 16.

7. Rousta N, Ferreira JA, Taherzadeh MJ. Production of L-carnitine-enriched edible filamentous fungal biomass through submerged cultivation. Bioengineered. 2021;12:358-68.

8. Saper RB, Eisenberg DM, Philips RS. Common dietary supplements for weight loss. Am Farm Physician. 2004;70:1731-8.

9. Strijbis K, Vaz FM, Distel B. Enzymology of the carnitine biosynthesis pathway. Life. 2010;62:35762.

10. Franken J, Burger A, Swiegers JH, Bauer FF. Reconstruction of the carnitine biosynthesis pathway from Neurospora crassa in the yeast Saccharomyces cerevisiae. Appl Microbiol Biotechnol. 2015;99:6377-89.

11. Krivoruchko A, Zhang Y, Siewers V, Chen Y, Nielsen J. Microbial acetyl-CoA metabolism and metabolic engineering. Metab Eng. 2015;28:28-42; doi:1016/j.ymben.2014.11.009.

12. Chen L, Zhang J, Chen WN. Engineering the Saccharomyces cerevisiae $\beta$-oxidation pathway to increase medium chain fatty acid production as potential biofuel. Plos One. 2014;9:doi:e84853. 10.1371/journal.pone.0084853.

13. Mlickova K, Roux E, Athenstaedt K, d'Andrea S, Daum G, Chardot T, Nicaud J-M. Lipid accumulation, lipid body formation, and acyl coenzyme a oxidases of the yeast Yarrowia lipolytica. Appl Environ Microbiol. 2004;70:3918-24.

14. Wang HJ, Le Dall MT, Waché Y, Laroche C, Belin JM, Gaillardin C, Nicau J-M. Evaluation of acyl coenzyme A oxidase (Aox) isozyme function in the n-alkane-assimilating yeast Yarrowia lipolytica. $J$ Bacteriol. 1999;181:5140-8.

15. Dulermo R, Gamboa-Melendez H, Ledesma-Amaro R, Thevenieau F, Nicaud J-M. Unraveling fatty acid transport and activation mechanisms in Yarrowia lipolytica. Biochim Biophys Acta. 2015;1851:1202-17. doi:10.1016/j.bbalip.2015.04.004. 
16. Dellomonaco C, Rivera C, Campbell P, Gonzalez R. Engineered respire-fermentative metabolism for the production of biofuels and biochemical from fatty acid-rich feedstock. Appl Environ Microbiol. 2010;76:5067-78.

17. Haddouche R. Delessert S, Sabirova J. Neuveglise C, Poirier Y. Nicaud J-M. Roles of multiple acyl-CoA oxidases in the routing of carbon flow towards $\beta$-oxidation and polyhydroxyalkanoate biosynthesis in Yarrowia lipolytica. FEMS Yeast Res. 2010;10:917-27.

18. Ledesma-Amaro R, Nicaud J-M. Yarrowia lipolytica as a biotechnological chassis to produce usual and unusual fatty acids. Prog Lipid Res. 2016;61:40-50. doi:10.1016/j.plipres.2015.12.001.

19. Bellou S, Triantaphyllidou I-E, Aggeli D, Elazzazy AM, Baeshen MN, Aggelis G. Microbial oils as food additives: recent approaches for improving microbial oil production and its polyunsaturated fatty acid content. Curr Opin Biotechnol. 2016;37:24-35.

20. Carsanba E, Papanikolaou S, Erten H. Production of oils and fats by oleaginous microorganisms with an emphasis given to the potential of the nonconventional yeast Yarrowia lipolytica. Crit Rev Biotechnol. 2018;38:1230-43.

21. Jach ME, Sajnaga E, Świder R, Baier A, Mickowska B, Juda M, Chudzik-Rząd B, Szyszka R, Malm A. Yarrowia lipolytica grown on biofuel waste as a source of single cell protein and essential amino acids for human diet. Saudi J Med Pharm Sci. 2017;3:1344-51.

22. Jach ME, Masłyk M, Juda M, Sajnaga E, Malm A. Vitamin B12-enriched Yarrowia lipolytica biomass obtained from biofuel waste. Waste Biomass Valori. 2020a;11:1711-6. doi:10.1007/s12649-0180521-5.

23. Jach ME, Serefko A. Nutritional yeast biomass: characterization and application. In: Grumezescu A, Holban AM, editors. Diet, Microbiome and Health. Handbook of food bioengineering. Elsevier: Academic Press; 2018. pp. 237-70.

24. Lopes M, Gomes AS, Silva CM, Bel I. Microbial lipids and added value metabolites production by Yarrowia lipolytica from pork lard. J Biotechnol. 2018;265:76-85.

25. Papanikolaou S, Aggelis G. Yarrowia lipolytica: A model microorganism used for the production of tailor-made lipids. Eur J Lipid Sci Technol. 2010;112:639-54. doi:10.1002/ejlt.200900197.

26. Jach ME, Sajnaga E, Janeczko M, Juda M, Kochanowicz E, Baj T, Malm A. Production of enriched in B vitamins biomass of Yarrowia lipolytica grown in biofuel waste. Saudi J Biol Sci. 2021. doi:10.1016/j.sjbs.2021.02.027.

27. Katre G, Joshi C, Khot M, Zinjarde S, RaviKumar A. Evaluation of single cell oil (SCO) from a tropical marine yeast Yarrowia lipolytica NCIM 3589 as a potential feedstock for biodiesel. AMB Expr. 2012;2:36. doi:10.1186/2191-0855-2-36.

28. Somba MK, Nikiema M, Nikiema M, Keita I, Mogmenga I, Sonagnon HS, Kouhounde SHS, Dabire Y, Coulibaly WH, Taale E, Traore AS. Production of single cell protein (SCP) and essentials amino acids from Candida utilis FMJ12 by solid state fermentation using mango waste supplemented with nitrogen sources. Afr J Biotechnol. 2018;17:716-23. 
29. EFSA. Safety of Yarrowia lipolytica yeast biomass as a novel food pursuant to Regulation (EU) 2015/2283. 2015; doi:10.2903/j.efsa.2019.5594.

30. Saygün A, Sahin-Yesilcubuk N, Aran N. Effects of different oil sources and residues on biomass and metabolite production by Yarrowia lipolytica YB 423 - 12. J Am Oil Chem Soc. 2014;91:1521-30.

31. Vasiliadou I, Bellou S, Daskalaki A, Tomaszewska-Hetman L, Chatzikotoula C, Kompoti B, Papanikolaou S, Vayenas D, Pavlou S, Aggelis G. Biomodification of fats and oils and scenarios of adding value on renewable fatty materials through microbial fermentations: modelling and trials with Yarrowia lipolytica. J Clean Prod. 2018;200:1111-29.

32. Tzirita M, Papanikolaou S, Chatzifragkou A, Quilty B. Waste fat biodegradation and biomodification by Yarrowia lipolytica and a bacterial consortium composed of Bacillus spp. and Pseudomonas putida. Eng Life Sci. 2018;18:932-42.

33. Groenewald M, Boekhout T, Neuvéglise C, Gaillardin C, van Dijk PWM, Wyss M. Yarrowia lipolytica: Safety assessment of an oleaginous yeast with a great industrial potential. Crit Rev Microbiol. 2014;40:187-206.

34. Xu P, Qiao K, Ahn WS, Stephanopoulos G. Engineering Yarrowia lipolytica as a platform for synthesis of drop-in transportation fuels and oleochemicals. PNAS. 2016;113:10848-53.

35. Jach ME, Baj T, Juda M, Świder R, Mickowska B, Malm A. Statistical evaluation of growth parameters in biofuel waste as a culture medium for improved production of single cell protein and amino acids by Yarrowia lipolytica. AMB Expr. 2020b;10:35. doi:10.1186/s13568-020-00968-x.

36. Papanikolaou S, Chevalot I,Komaitis M, Marc I, Aggelis G. Single cell oil production by Yarrowia lipolytica growing on an industrial derivative of animal fat in batch cultures. Appl Microbiol Biotechnol. 2002;58:308-12. doi:10.1007/s00253-001-0897-0.

37. Papanikolaou S, Muniglia L, Chevalot I, Aggelis G, Marc I. Accumulation of a cocoa-butter-like lipid by Yarrowia lipolytica cultivated on agro-industrial residues. Curr Microbiol. 2003;46:124-30.

38. Zhao MX, Chi Z, Chi ZM, Madzak C. The simultaneous production of single-cell protein and a recombinant antibacterial peptide by expression of an antibacterial peptide gene in Yarrowia lipolytica. Proc Biochem. 2016;48:212-7.

39. Lopes M, Miranda SM, Alves JM, Pereira AS, Belo I. Waste cooking oils as feedstock for lipase and lipid-rich biomass production. Eur J Lipid Sci Technol. 2019;121:1800188. doi:101002/ejlt.201800188. - .

40. Papanikolaou S, Chevalot I, Komaitis M, Aggelis G, Marc I. Kinetic profile of the cellular lipid composition in an oleaginous Yarrowia lipolytica capable of producing a cocoa-butter substitute from industrial fats. Antonie Van Leeuwenhoek. 2001;80:215-24.

41. Daskalaki A, Perdikouli N, Aggeli D, Aggelis G. Laboratory evolution strategies for improving lipid accumulation in Yarrowia lipolytica. Appl Microbiol Biotechnol. 2019;103:8585-96.

42. Dourou M, Aggeli D, Papanikolaou S, Aggelis G. Critical steps in carbon metabolism affecting lipid accumulation and their regulation in oleaginous microorganisms. Appl Microbiol Biotechnol. 2018;102:2509-23. 
43. Dominguez A, Deive FJ, Angeles Sanroman M, Longo MA. Biodegradation and utilization of waste cooking oil by Yarrowia lipolytica CECT 1240. Eur J Lipid Sci Technol. 2010;112:1200-8.

44. Zhang Q, Sun X, Xiao X, Zheng J, Li M, Yu M, Ping F, Wang Z, Qi C, Wang T, Wang X. The effect of maternal chromium status on lipid metabolism in female elderly mice offspring and involved molecular mechanism. Biosci Rep. 2017;28(2):37. doi:10.1042/BSR20160362. BSR20160362.

45. Vlatka GZ, Vesna ST, Sloboda G, Lavoslav L, Damir K. Chromium uptake by Saccharomyces cerevisiae and isolation of glucose tolerance factor from yeast biomass. J Biosci. 2001;26:217-23.

\section{Figures}
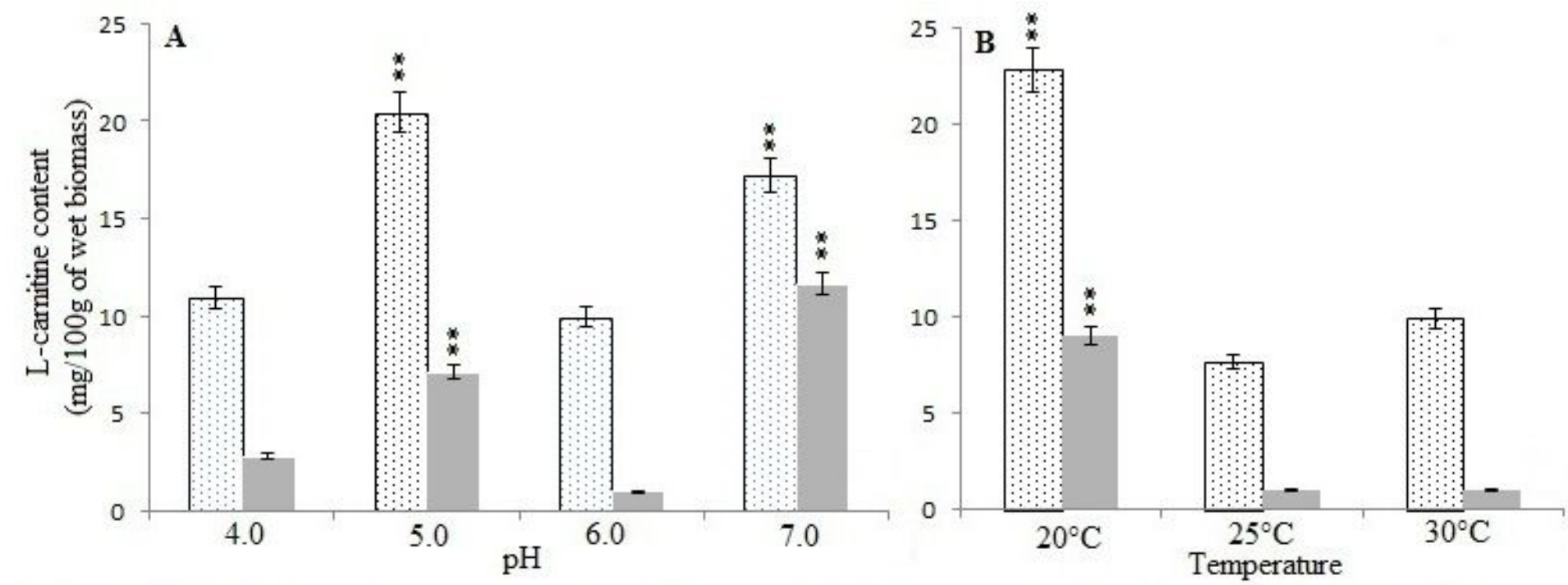

\section{Figure 1}

Total free L-carnitine concentration in wet biomass of Y. lipolytica strains cultured in the YPD medium at different conditions. A. constant temperature $\left(30^{\circ} \mathrm{C}\right)$ and variable $\mathrm{pH}$ values. B. constant $\mathrm{pH}(6.0)$ values and variable temperature. Y. lipolytica ATCC 9793 (dotted squares); Y. lipolytica A-101 (filled squares). ** $P<0.01$ indicate significant difference compared to reference cultivation. 


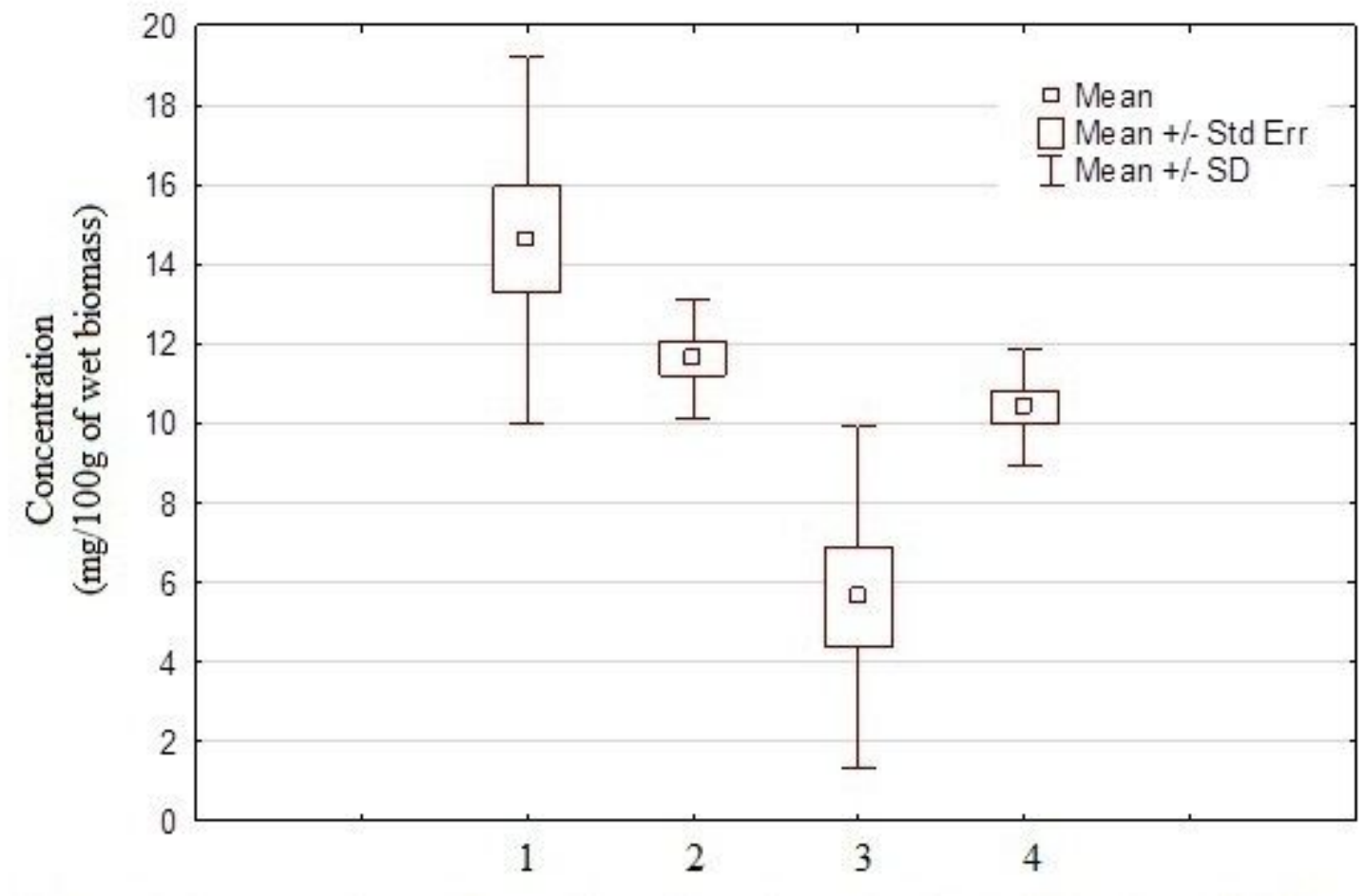

Figure 2

Average values of L-carnitine and protein production by Y. lipolytica A-101 and ATCC 9793 strains growing on YPD medium, shown as irrespective of the culture parameters. 1. L-carnitine concentration in Y. lipolytica ATCC 9793 biomass. 2. Protein content in Y. lipolytica ATCC 9793 biomass [21]. 3. L-carnitine concentration in Y. lipolytica A-101 biomass. 4. Protein content in Y. lipolytica A-101 biomass [21].
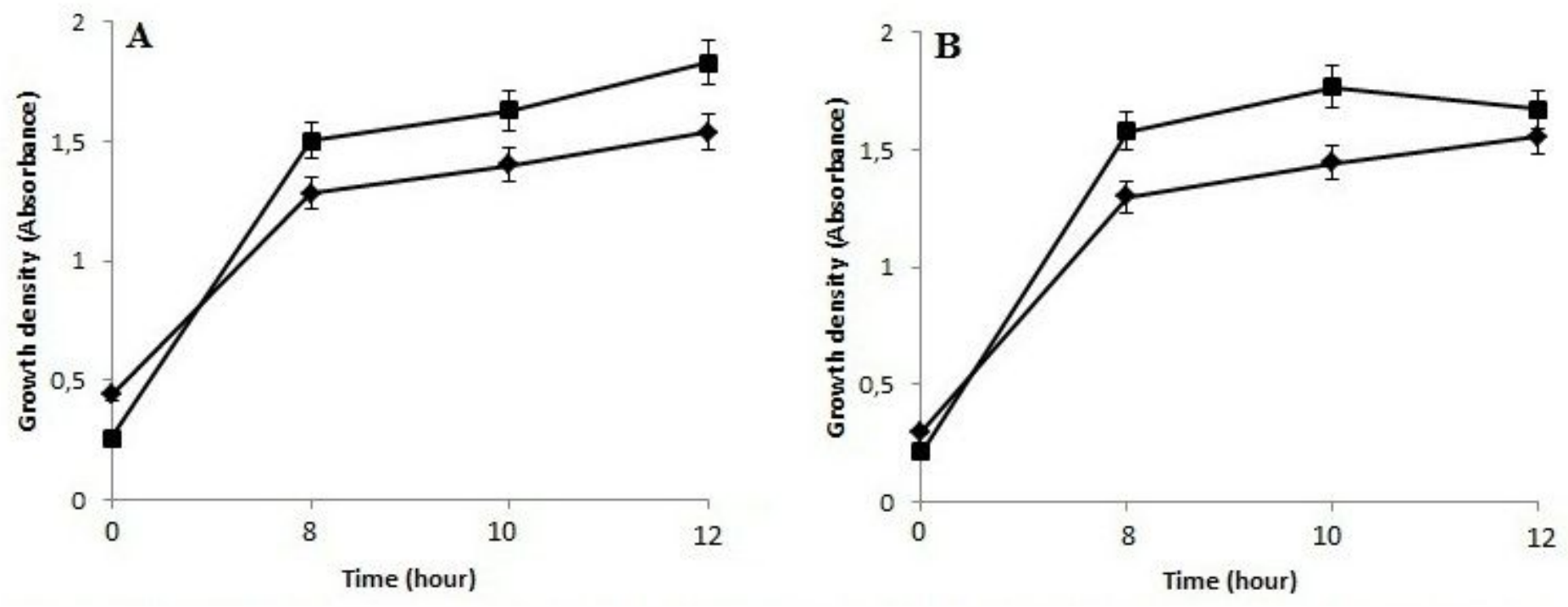

Figure 3

Growth density of Y. lipolytica. A. Y. lipolytica ATCC 9793; B. Y. lipolytica A-101 cultured in SK medium (biofuel waste), ( $\left.\mathrm{pH} 6.0,30^{\circ} \mathrm{C}\right)$ $(0.1 \mathrm{~g} / \mathrm{L})$, iron(II) sulfate $(0.01 \mathrm{mg} / \mathrm{L})$, and L-ascorbic acid $(0.002 \mathrm{~g} / \mathrm{L})$. 